\title{
PROTEIN SYNTHESIS INHIBITORS INDUCE INTERCELLULAR ADHESION MOLECULE-1 GENE EXPRESSION IN HUMAN SQUAMOUS CELL CARCINOMA CELL LINES
}

\author{
Hiroshi Fujisawa ${ }^{1}$, Kazuhisa NaKayama ${ }^{2}$, Takashi Nomura ${ }^{1}$ and Fujio Otsuka ${ }^{1}$ \\ ${ }^{1}$ Department of Dermatology, Institute of Clinical Medicine and ${ }^{2}$ Institute of Biological Sciences and Gene Experiment Center, \\ University of Tsukuba, Tsukuba, Ibaraki 305, Japan
}

\begin{abstract}
In order to determine whether induction of intercellular adhesion molecule-1 (ICAM-1) mRNA by interferon $-\gamma$ or tumor necrosis factor $\alpha$ is a primary genetic response or requires a prior synthesis of other gene products, we examined the effects of the protein synthesis inhibitors, cycloheximide and puromycin, on the ICAM-1 mRNA induction in cell lines derived from human squamous cell carcinoma. Unexpectedly, treatment with either cycloheximide or puromycin alone led to a marked increase in the level of ICAM-1 mRNA. The mRNA induction by both protein synthesis inhibitors occurred in a dose-dependent manner. The level of ICAM-1 mRNA was maximum at $4 \mathrm{~h}$ after the addition of the inhibitor, and then gradually decreased. These observations suggest the presence of a cellular factor(s) which tonically suppresses the ICAM-1 gene expression.
\end{abstract}

Keratinocyte intercellular adhesion molecule-1 (ICAM-1) plays an important role in skin diseases (11). Keratinocyte ICAM-1 mRNA is known to be induced by cytokines, interferon- $\gamma$ (IFN- $\gamma$ ) and tumor necrosis factor- $\alpha$ (TNF- $\alpha$ ) (6). However, it remains to be elucidated whether the induction of ICAM-1 mRNA by the cytokines is a primary genetic response or require the prior synthesis of other gene products.

To address this issue, we studied the effects of protein synthesis inhibitors, cycloheximide (CHX) and puromycin (PM), on the ICAM-1 mRNA induction by the cytokines in human squamous cell carcinoma cell lines, DJM-1 and A431. However, this study led us to an unexpected finding, i.e., when these cell lines were treated with either CHX or PM alone, a marked increase in the level of ICAM-1 mRNA was observed.

Abbreviations: ICAM-1, intercellular adhesion molecule1 ; IFN- $\gamma$, interferon- $\gamma$; TNF- $\alpha$, tumor necrosis factor- $\alpha$; CHX, cycloheximide; PM, puromycin

\section{MATERIALS AND METHODS}

\section{Cytokines and Chemicals}

Human recombinant IFN- $\gamma$ was provided by Takeda Chemical Industries (Osaka). Human TNF$\alpha$ was a gift from Mochida Pharmaceutical (Tokyo). CHX and PM were purchased from Sigma Chemical (St. Louis, MO).

\section{Cell Culture}

Human squamous cell carcinoma lines, A431 and DJM-1, were cultured in Dulbecco's modified Eagle's medium supplemented with $10 \%$ fetal calf serum, $100 \mathrm{IU} / \mathrm{ml}$ penicillin, and $100 \mu \mathrm{g} / \mathrm{ml}$ streptomycin at $37^{\circ} \mathrm{C}$ in a humidified atmosphere containing $5 \% \mathrm{CO}_{2}$.

\section{RNA Isolation and Northern Blot Analysis}

The cells plated on a $10-\mathrm{cm}$ dish were incubated for $48 \mathrm{~h}$, and the medium was exchanged with a fresh medium containing an agent or agents. After the treatment, total cellular RNA was isolated from 


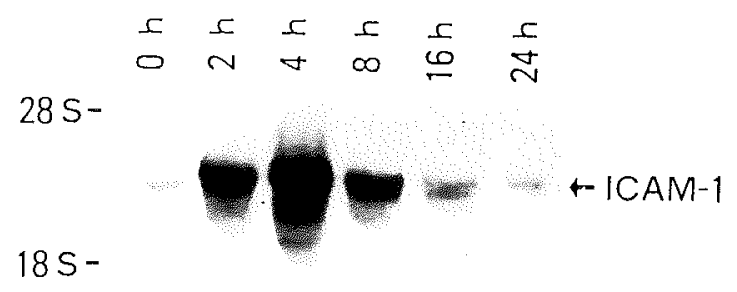

$18 \mathrm{~S}-$

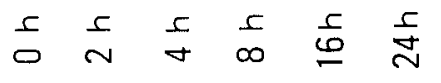

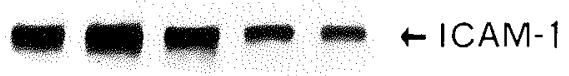

$18 S-$

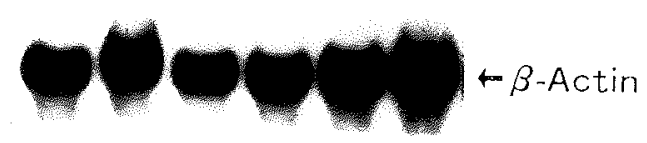

A

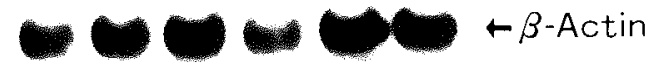

B

Fig. 1 Time course of ICAM-1 mRNA induction by cytokines. DJM-1 cells were incubated for indicated periods in the presence of IFN- $\gamma(10 \mathrm{U} / \mathrm{ml})(\mathrm{A})$ or TNF- $\alpha(50 \mathrm{U} / \mathrm{ml})(\mathrm{B})$. After the treatment, total cellular RNA was extracted from the cells, and subjected to Northern blot analysis using the cDNA probe for ICAM-1 or $\beta$-actin as described under Materials and Methods.

the cells by the method of Chomczynski and Sacchi (4). RNAs (10 $\mu \mathrm{g}$ each) were denatured with glyoxal, electrophoresed on a 1.2\% agarose gel, and blotted onto a GeneScreenPlus membrane (Du Pont-New England Nuclear) as described previously (7). The blot was hybridized with the $\left[{ }^{32}\right.$ P]labeled cDNA probe specific for ICAM-1 (13) (a gift from Dr B. Seed, Massachusetts General Hospital, Boston, MA) or for $\beta$-actin (15) (a gift from Dr K. Tokunaga, Chiba Cancer Center Research Institute, Japan) under the previously described conditions (7), and washed sequentially in $2 \times \mathrm{SSC}(300 \mathrm{mM} \mathrm{NaCl}, 30 \mathrm{mM}$ sodium citrate) at room temperature for $10 \mathrm{~min}, 2 \times \mathrm{SSC}, 1 \% \mathrm{SDS}$ at $60^{\circ} \mathrm{C}$ for $60 \mathrm{~min}$, and $0.1 \times \mathrm{SSC}$ at room temperature for $10 \mathrm{~min}$. The relative RNA level was roughly estimated by densitometric scanning of each band in the resulting autoradiogram.

\section{RESULTS}

Time Course of the ICAM-1 mRNA Induction by Cytokines

In keratinocytes, ICAM-1 mRNA is known to be induced by the treatment with cytokines, such as IFN- $\gamma$ or TNF- $\alpha$ (2). We first examined the effects of the cytokines on the ICAM-1 mRNA expression in a human squamous cell carcinoma cell line, DJM-1. In unstimulated DJM-1 cells, ICAM-1
mRNA was expressed at a relatively low level. By the treatment with either $10 \mathrm{U} / \mathrm{ml}$ IFN- $\gamma$ (Fig. 1A) or $50 \mathrm{U} / \mathrm{ml} \mathrm{TNF-} \alpha$ (Fig. 1B), the level of ICAM-1 mRNA gradually increased, peaked at $4 \mathrm{~h}$, then gradually decreased. The maximum levels by the treatment with IFN- $\gamma$ and TNF- $\alpha$ were estimated to be approximately 100-fold and 25-fold higher, respectively, than the basal level. Reprobing the blots with the $\beta$-actin probe demonstrated that the induction was specific for ICAM-1 mRNA.

\section{The Influence of Protein Synthesis Inhibitors on ICAM-1 mRNA Induction by Cytokines}

To determine whether the ICAM-1 mRNA induction by the cytokines is a primary genetic response or not, we then studied the influence of the protein synthesis inhibitor, CHX, on the ICAM-1 mRNA induction in DJM-1 cells (Fig. 2). Unexpectedly, the treatment of the cells with CHX $(5 \mu \mathrm{g} / \mathrm{ml})$ alone led to a marked increase in the level of ICAM-1 mRNA. Reprobing the blot with the $\beta$ actin probe confirmed that the differences in the mRNA level did not result from the differences in the amount of the RNAs loaded. To determine if this phenomenon is specific for CHX, we then examined the effects of another protein synthesis inhibitor, PM. Similar results were obtained using PM $(10 \mu \mathrm{g} / \mathrm{ml})$ (data not shown). Since CHX and 


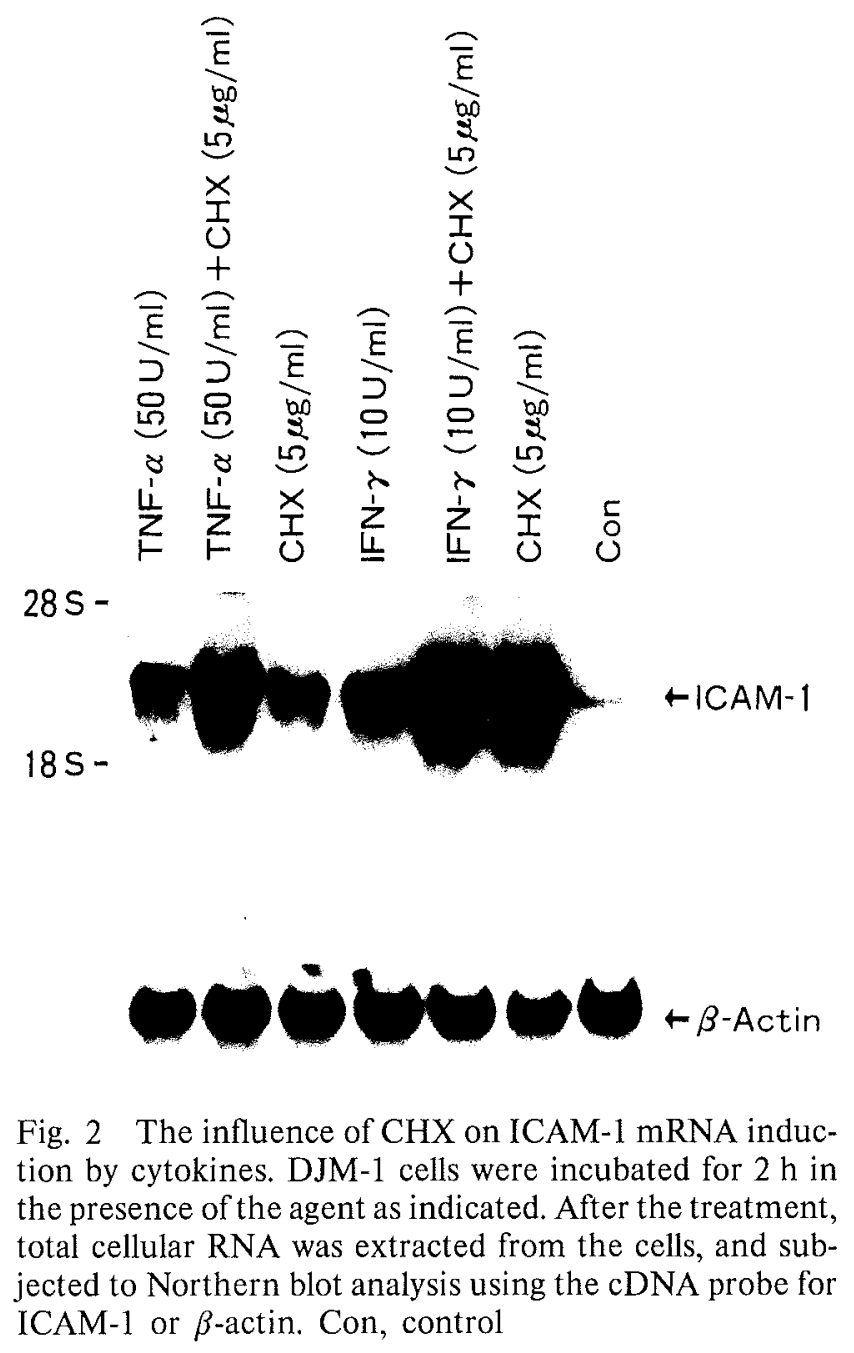

Fig. 2 The influence of CHX on ICAM-1 mRNA induction by cytokines. DJM- 1 cells were incubated for $2 \mathrm{~h}$ in the presence of the agent as indicated. After the treatment, ICAM-1 or $\beta$-actin. Con, control

PM inhibit protein synthesis by different mechanisms (CHX inhibits the transfer reaction in elongation of peptide chains and stabilizes polysomal RNA, whereas PM produces premature dissociation of the peptide-mRNA-ribosome complex.), it is unlikely that the effect of CHX distinct from its inhibition of translation is responsible for these observations.

\section{Time Course of the ICAM-1 mRNA Induction by the Protein Synthesis Inhibitors}

We then examined the unexpected phenomenon in detail. As shown in Fig. 3, induction of ICAM-1 mRNA by CHX in DJM-1 cells was transient; the mRNA level gradually increased within $4 \mathrm{~h}$, then decreased in the presence of CHX $(0.8 \mu \mathrm{g} / \mathrm{ml})$. A similar pattern of the induction was observed in the presence of PM $(1 \mu \mathrm{g} / \mathrm{ml})$ (data not shown).

Dose Dependence of the Effects of the Protein Synthesis Inhibitors

As shown in Fig. 4, the induction of ICAM-1 mRNA by CHX or PM in DJM-1 cells occurred in a dose-dependent manner. Both the mRNA levels at $4 \mathrm{~h}$ of incubation in the presence of $5 \mu \mathrm{g} / \mathrm{ml}$ of CHX and $15 \mu \mathrm{g} / \mathrm{ml}$ of PM were approximately 200fold higher than the basal level.

All the experiments carried out using DJM-1 cells were also done with another squamous cell carcinoma cell line, A431. The results with A431 cells were similar to those with DJM-1 cells (data not shown), suggesting that the effects of the inhibitors on the ICAM-1 mRNA expression do not depend on the used cell lines. 


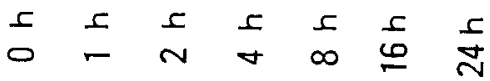

$28 \mathrm{~S}-$

$18 \mathrm{~S}-$

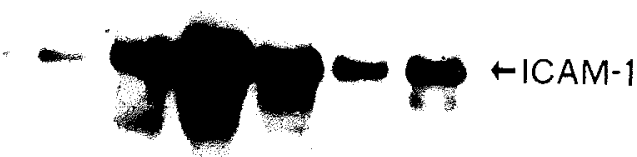

$\omega \omega O+\beta$ Actin

Fig. 3 Time course of ICAM-1 mRNA induction by CHX. DJM-1 cells were incubated for indicated periods in the presence of CHX $(0.8 \mu \mathrm{g} / \mathrm{ml})$. After the treatment, total cellular RNA was extracted from the cells, and subjected to Northern blot analysis using the cDNA probe for ICAM-1 or $\beta$-actin.

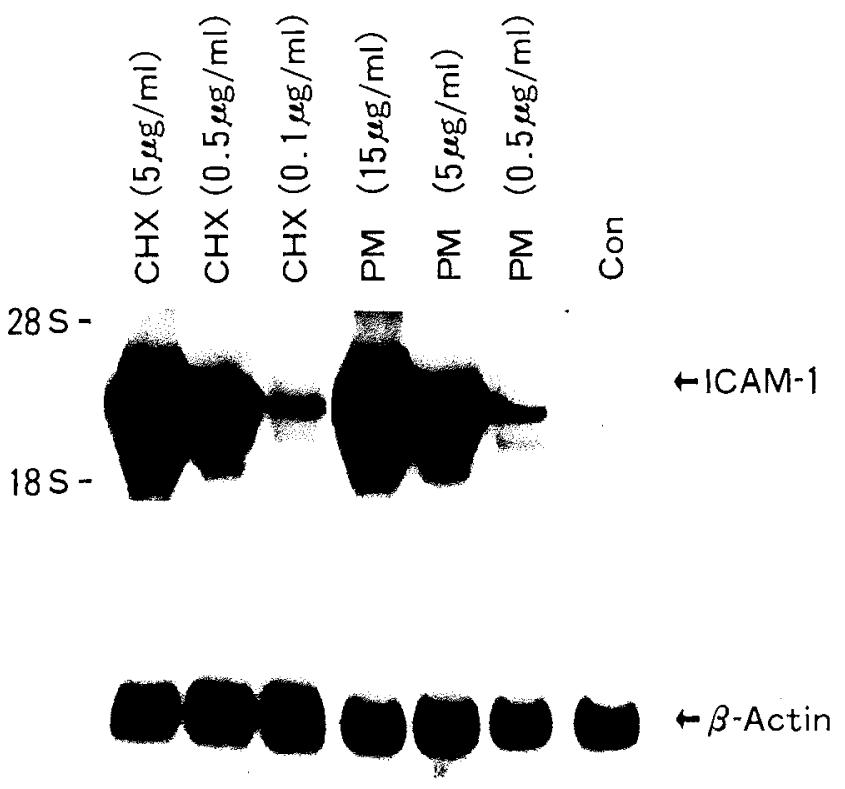

Fig. 4 Effects of CHX or PM concentrations on ICAM-1 mRNA expression. DJM-1 cells were incubated for $4 \mathrm{~h}$ in the presence of the indicated concentrations of $\mathrm{CHX}$ or PM. After the treatment, total cellular RNA was extracted from the cells, and subjected to Northern blot analysis using the cDNA probe for ICAM-1 or $\beta$-actin. Con, control 


\section{DISCUSSION}

In the course of this study, we unexpectedly found that in squamous cell carcinoma cell lines, DJM-1 and A431, the protein synthesis inhibitors, CHX and PM, markedly increased the level of ICAM-1 mRNA in a dose-dependent manner (Figs. 2 and 4). The maximum level after the treatment was approximately 200 -fold higher than the basal level (Fig. 4). Time course experiments showed that after the addition of either inhibitor, the induction of the level of ICAM-1 mRNA was transient (peaking at $4 \mathrm{~h}$ ) (Fig. 3). Since such treatments did not affect the level of $\beta$-actin mRNA as a control, the increase in the ICAM-1 mRNA level could not reflect a generalized increase in the total cellular mRNA level. Moreover, since CHX and PM inhibit protein synthesis by different mechanisms, the above observations could not be explained by unknown effect(s) of these agents distinct from inhibition of protein synthesis. One of the possible explanations for these observations is that the expression of ICAM-1 gene may be tonically suppressed by a labile, negative transcription factor(s).

CHX treatment is known to lead to enhanced expression of various genes, such as methallothionein (10), low density lipoprotein receptor (9), cmyc (8), CD11a (1), IFN- $\beta$ (12), ets-2 (3), glycoprotein hormone $\alpha$-subunit (5), and histone (14). Although several reports have suggested that the inhibition of protein synthesis by $\mathrm{CHX}$ or other agents alters mRNA levels through effects on transcription of genes $(5,9,10,12)$ or stability of mRNAs $(8,10,14)$, the detailed mechanisms of the enhanced gene expression by the protein synthesis inhibitors remain to be elucidated. Compared with the degree of induction in other mRNAs by the treatment with the inhibitors (ranged from 2- to 20 fold), that in the ICAM-1 mRNA observed in this study appears to be extremely large $(\sim 200$-fold at the maximum level). The expression of ICAM-1 gene could be regulated by a mechanism somewhat different from those of other genes. Further characterization of the molecular events accounting for these observations may provide additional insight into the regulation of a number of genes activated by the protein synthesis inhibitors.

We would like to thank Professor H. Yaoita (Jichi Medical School) for having kindly provided the DJM-1 cells. This work was supported in part by grants from the University of Tsukuba Project Research and from the Shiseido Company.
Received 27 Janwary 1993; and accepted 9 February 1993

\section{REFERENCES}

1. Back A. L., Gollahon K. A. and Hickstein D. D. (1992) Regulation of expression of the leukocyte integrin CD11a (LFA-1) molecule during differentiation of HL-60 cells along the monocyte/macrophage pathway. J. Immunol. 148, 710-714

2. Barker J, N. W. N., Sarma V., Mitra R. S., Dixit V. M. and NickolofF B. J. (1990) Marked synergism between tumor necrosis factor- $\alpha$ and interferon- $y$ in regulation of keratinocyte-derived adhesion molecules and chemotactic factor's. J. Clin. Invest. 85, 605-608

3. Bhat N. K., Fisher R. J., Fujiwara S., Ascione R. and PAPAS T. S. (1987) Temporal and tissue-specific expression of mouse ets genes. Proc. Natl. Acad. Sci. USA 84, 31613165

4. Chomczynski P. and SACCHI N. (1987) Single-step method of RNA isolation by acid guanidinium thiocyanate-phenolchloroform extraction. Anal. Biochem. 162, 156-159

5. Cox G. S., Cosgrove D. E., Sullivan T. T. and HaAs M. J. (1990) Induction by cycloheximide of the glycoprotein hormone $\alpha$-subunit gene in human tumor cell lines and identification of a possible negative regulatory factor. J. Biol. Chem. 265, 13190-13197

6. Dustin M. L., Singer K. H., Tuck D. T. and Springer T. A. (1988) Adhesion of T lymphoblasts to epidermal keratinocytes is regulated by interferon $\gamma$ and is mediated by intercellular adhesion molecule 1 (ICAM-1). J. Exp. Med. 167, 1323-1340

7. Hatsuzawa K., Hosaka M., Nakagawa T., Nagase M., Shoda A., MuraKami K. and NaKayama K. (1990) Structure and expression of mouse furin, a yeast Kex2-related protease. J. Biol. Chem. 265, 22075-22078

8. Kelly K., Cochran B. H., Stiles C. D. and Leder P. (1983) Cell-specific regulation of the $c-m y c$ gene by lymphocyte mitogens and platelet-derived growth factor. Cell 35, 603610

9. Mazzone T, Basheeruddin K. and Duncan H. (1989) Inhibitors of translation induce low density lipoprotein receptor gene expression in human skin fibroblasts. J. Biol. Chem. 264, 15529-15534

10. McCormick C. C., Salati L. M. and Goodridge A. G. (1991) Abundance of hepatic metallothionein mRNA is increased by protein-synthesis inhibitors. Biochem. J. 273, 185-188

11. Nickoloff B. J., Griffiths C. E. M. and Barker J. N. W. N. (1990) The role of adhesion molecules, chemotactic factors, and cytokines in inflammatory and neoplastic skin disease-1990 update. J. Invest. Dermatol. 94, 151S$157 \mathrm{~S}$

12. Ringold G. M., Dieckmann B., Vannice J. L., Trahey M. and MCCormick F. (1984) Inhibition of protein synthesis stimulates the transcription of human $\beta$-interferon genes in Chinese hamster ovary cells. Proc. Natl. Acad. Sci. USA 81, 3964-3968

13. Simmons D., MAKGoBa M. W. and SeEd B. (1988) ICAM, an adhesion ligand of LFA-1, is homologous to the neural cell adhesion molecule NCAM. Nature 331, 624-627

14. Stimac E., Groppi V. E. and Coffino P. (1984) Inhibition of protein synthesis stabilizes histone mRNA. Mol. Cell. Biol. 4, 2082-2090 
15. Tokunaga K., Taniguchi H., Yoda K., Shimizu M. and SAKIYAMA S. (1986) Nucleotide sequence of a full-length
cDNA for mouse cytoskeletal $\beta$-actin mRNA. Nucleic Acids Res. 14, 2829 